Research Article

Open Access

\title{
Formulation and Optimization of Controlled Porosity Osmotic Pump Tablets of Lamivudine using Sodium Chloride as Osmogen for the Treatment of AIDS
}

\author{
Chinmaya Keshari Sahoo ${ }^{1}$, Nalini Kanta Sahoo ${ }^{2 \star}$, Surepalli Ram Mohan Rao ${ }^{3}$ and Muvvala Sudhakar ${ }^{4}$ \\ 'Ph.D Scholar, Department of Pharmaceutics, Faculty of Pharmacy, University College of Technology, Osmania University, Hyderabad, \\ Telangana, India \\ ${ }^{2}$ Professor \& HOD, Department of Pharmaceutical Analysis and Quality assurance, MLR Institute of Pharmacy, Dundigal, Medchal, \\ Telangana, India \\ ${ }^{3}$ Professor, Mekelle Institute of Technology, Mekelle University, Mekelle, Ethiopia \\ ${ }^{4}$ Professor and Principal, Department of Pharmaceutics, Malla Reddy College of Pharmacy, Maisammaguda, Secunderabad, Telangana, India
}

Article Info
*Corresponding author:
Nalini Kanta Sahoo
Professor \& HOD
Department of Pharmaceutical Analysis
and Quality Assurance
MLR Institute of Pharmacy
Dundigal, Medchal
Telangana, India
Tel: 9550741536
Email: sahoo.nalini@gmail.com

Received: October 24, 2018

Accepted: October 29, 2018

Published: October 31, 2018

Citation: Sahoo CK, Sahoo NK, Rao SRM, Sudhakar M. Formulation and Optimization of Controlled Porosity Osmotic Pump Tablets of Lamivudine using Sodium Chloride as Osmogen for the Treatment of AIDS. Madridge J Nov Drug Res. 2018; 2(1): 94-101. doi: $10.18689 / \mathrm{mjndr}-1000114$

Copyright: ( 92018 The Author(s). This work is licensed under a Creative Commons Attribution 4.0 International License, which permits unrestricted use, distribution, and reproduction in any medium, provided the original work is properly cited.

Published by Madridge Publishers

\begin{abstract}
The present study was undertaken to develop controlled porosity osmotic pump tablets of lamivudine a nucleoside reverse transcriptase inhibitor for the treatment of acquired immune deficiency syndrome (AIDS). The tablets were prepared by wet granulation method using HPMC E5LV, and osmogen was prinicipal ingredients a dose of $300 \mathrm{mg}$ once daily. The coating solution of core tablets were prepared by using cellulose acetate, poly ethylene glycol of different grades, sorbitol and acetone to quantity sufficient for different batches. The prepared tablets were evaluated for pre compression parameters, post compression parameters, in vitro drug release study and scanning electron microscopy study. Among developed formulations LS4 batch show $98.26 \%$ drug release in $12 \mathrm{hrs}$. The in vitro release kinetics were analyzed for different batches by different pharmacokinetic models such as zero order, first order, Higuchi, Korsmeyer Peppas and Hixon Crowell model. The results of optimized formulation follow Higuchi kinetics and which is independent of the $\mathrm{pH}$ and agitation intensity. Short term stability study (at $40 \pm 2^{\circ} \mathrm{C} / 75 \pm 5 \% \mathrm{RH}$ for three months) on the best formulation indicated that there was no significant changes in thickness, friability, weight variation, drug content and in vitro drug release.
\end{abstract}

Keywords: AIDS; Wet granulation; In vitro drug release; Stability study.

\section{Inroduction}

The discovery of HIV as the causative agent of AIDS by Sinoussi et al. in 1983 [1], HIV/ AIDS is a major threat to population health in the world. Over the past 35 years AIDS is spreading like a pandemic disease and creating major global health problems in the world. WHO estimate in 2015 showed that 36.7 million people globally [2] were living with HIV, AIDS killed 1.1 million people died from AIDS related illnesses and 35 million people have died from AIDS related illness since start from epidemic. In AIDS patient experiences infection in immune system causing decline CD4+ cell count of less than 200 cells/ $\mu \mathrm{L}$ in blood. The most common initial conditions of AIDS are pneumocystis pneumonia (40\%), cachexia in the form of HIV wasting syndrome (20\%), respiratory tract infections and esophageal candidiasis. Opportunistic infections may be caused by bacteria, viruses, fungi and parasites. These infections affect nearly every organ system, e.g. brain, eye, liver, genitals, skin etc. Patients with AIDS have an increased risk of developing various viral 
induced cancers including Kaposi's sarcoma. Symptoms occur in $40-90 \%$ of cases and most commonly include fever, large tender lymph nodes, throat inflammation, a rash, headache, sores of the mouth and genitals [3], etc. The transmission of AIDS is due to via unprotected sexual intercourse (including anal and even oral sex), contaminated blood transfusions, hypodermic needles and from mother to child during pregnancy, delivery or breastfeeding. The management of AIDS can be controlled by antiretroviral therapy, male circumcision, needle exchange program, use of diaphragms, topical protection, use of condoms and alternative medicine.

Oral route is the most convenient route and most extensively used for the administration of various drugs. Oral conventional doses are usually administered 2 or more than 2 times daily which causes a large fluctuations in drug plasma concentration and may cause side effects. Hence controlled drug delivery systems are used to avoid these limitations in conventional drug delivery system. Controlled release dosage forms [4] provide prolong action of drugs and offer continuous release of their active ingredients at predetermined rate and predetermined time of zero order drug release. Among several controlled drug delivery systems osmotic controlled drug delivery system (OCDDS) utilizes principle of osmotic pressure for controlled delivery of active ingredients. OCDDS can deliver the drug in a large extent and the delivery nature is independent of the physiological factors of gastrointestinal tract, independent of $\mathrm{pH}$, hydrodynamic condition of the body and agitational intensity.

Current Highly active antiretroviral therapy (HAART) allows controlling viral replication of HIV-1. The present study is to develop controlled porosity osmotic pump tablets of lamivudine. CPOP tablet is a novel drug delivery system with eternally drug delivery rate as characteristic and controlled with the osmotic pressure difference between inside and outside of SPM as drug delivery power. CPOP tablets were developed where the delivery orifices were formed by the incorporation of a leachable component in SPM. The core is coated with cellulose acetate containing in situ micro pore former sorbitol. To increase drug release sodium chloride was chosen as osmotic agent who can generate high osmotic pressure gradient to deliver poorly or moderately water soluble drugs. Once CPOP tablets come in contact with the aqueous environment [5] of biological system the water soluble component dissolves and an osmotic pumping system is created in the core. Hence water diffuses into the core through the micro porous membrane setting up an osmotic gradient and thereby controlling the release of drug. The rate of drug delivery depends upon the factors such as water permeability of the semi permeable membrane, osmotic pressure of core formulation, thickness and total area of coating.

Lamivudine is a synthetic nucleoside analogue and is phosphorylated intra cellularly to its active $5^{\prime}$-triphosphate metabolite, lamivudine triphosphate (L-TP). This nucleoside analogue is incorporated into viral DNA by HIV reverse transcriptase resulting in DNA chain termination [6]. The present research aimed to design CPOP tablets of lamivudine by wet granulation method containing dose of $300 \mathrm{mg}$ once daily. Lamivudine has bioavailability of $86 \%$, protein binding of $36 \%$ and the biological half life is between $5-7 \mathrm{hrs}$. Hence it can be given to control the concentration of drug at the site of action. The main objective of the present study was to develop controlled porosity-based osmotically controlled release tablets of lamivudine.

\section{Materials and Methods}

\section{Materials}

Lamivudine was obtained from Hetero Drugs Pvt. Ltd. India., Sodium chloride and mannitol was obtained from Qualigens Fine Chemicals, India. Cellulose acetate (CA) was obtained from Eastman Chemical Inc, Kingsport, TN. Sorbitol, magnesium stearate, talc, HPMCE5LV and polyethylene glycol (PEG) 400, 600, 4000, 6000 were purchased from S.D. Fine Chemicals Ltd, Mumbai, India., Microcrystalline cellulose (MCC) and starch were purchased from Signet Pharma, Mumbai, India. All other solvents and reagents used were of analytical grade.

\section{Compatibility studies}

Fourier Transform Infrared Spectroscopy (FTIR) [7]: In this method individual samples, individual excipients and the mixture of drug and excipients were ground mixed thoroughly with potassium bromide (1:100) for 3-5 mins in a mortar and compressed into disc by applying pressure of $10 \mathrm{~kg} / \mathrm{cm}$ in hydraulic press. The pellet was kept in the sample holder and scanned from 4000 to $400 \mathrm{~cm}^{-1}$ in FTIR spectrophotometer (Bruker, Germany).

Differential Scanning Calorimetry (DSC): Physical mixtures [8] of drug and individual excipients in the ratio of 1:1 were taken and examined in DSC (Shimadzu DSC-50, Japan). The sample pan was crimped for effective heat conduction and scanned in the temperature range of $50-300^{\circ} \mathrm{C}$. Heating rate of $20^{\circ} \mathrm{C} \mathrm{min}{ }^{-1}$ was used and the thermogram obtained was reviewed for evidence of any interactions. Then the themo grams were compared with pure samples versus optimized formulation.

\section{Methods}

Preparation of osmotic pump tablets: The tablets were prepared by wet granulation [9] technique. Required quantities of ingredients mentioned in table- 1 were passed through sieve No.30 and lubricant and glidant were passed through sieve No.80. The ingredients were manually blended homogenously in a mortar by way of geometric dilution except lubricant (magnesium stearate), glidant (talc). The mixture was moistened with aqueous solution and granulated through sieve No.30 and dried in a hot air oven at $60^{\circ} \mathrm{C}$ for sufficient (3-4 hrs). The dried granules were sifted through sieve No.30 and mixed with talc and magnesium stearate. The homogenous blend was then compressed into round tablets with standard concave punches using 10 station rotary compression machines (Mini press, Karnavati, India). 
Table 1. Composition of osmotic pump lamivudine tablets

\begin{tabular}{|l|c|c|c|c|c|}
\hline Ingredients (mg) & LS1 & LS2 & LS3 & LS4 & LD5 \\
\hline LM & 300 & 300 & 300 & 300 & 300 \\
\hline MCC & 190 & 165 & 140 & 115 & 215 \\
\hline Starch & 25 & 25 & 25 & 25 & 25 \\
\hline HPMC E5LV & 100 & 100 & 100 & 100 & 100 \\
\hline Sodium chloride & 25 & 50 & 75 & 100 & 0 \\
\hline Magnesium stearate & 5 & 5 & 5 & 5 & 5 \\
\hline Talc & 5 & 5 & 5 & 5 & 5 \\
\hline Total weight (mg) & 650 & 650 & 650 & 650 & 650 \\
\hline
\end{tabular}

Coating of core tablets [10]: The coating solution was prepared taking required ingredients from table 2 and acetone was added quantity sufficient maintaining proper viscosity of solution. The coatings of tablets were performed by spray pan coating in a perforated pan (GAC-205, Gansons Ltd, Mumbai, India). Hot air is supplied to tablet bed by rotating lower speed 5-8 rpm initially. The coating of tablets was carried out with the rotation speed of 10-12 rpm. The spray rate and atomizing air pressure were $4-6 \mathrm{ml} / \mathrm{min}$ and $1.75 \mathrm{~kg} / \mathrm{cm}^{2}$ respectively. Inlet and outlet air temperature were $50^{\circ} \mathrm{C}$ and $40^{\circ} \mathrm{C}$ respectively. Coated tablets were dried at $50^{\circ} \mathrm{C}$ for $12 \mathrm{hrs}$.

Table 2. Coating composition for controlled porosity osmotic pump tablets

\begin{tabular}{|l|c|c|c|c|c|c|c|}
\hline $\begin{array}{l}\text { Formulation } \\
\text { code }\end{array}$ & $\begin{array}{c}\text { CA } \\
(\mathbf{g})\end{array}$ & $\begin{array}{c}\text { PEG 400 } \\
(\mathbf{g})\end{array}$ & $\begin{array}{c}\text { PEG 600 } \\
(\mathbf{g})\end{array}$ & $\begin{array}{c}\text { PEG 4000 } \\
(\mathbf{g})\end{array}$ & $\begin{array}{c}\text { PEG 6000 } \\
(\mathbf{g})\end{array}$ & $\begin{array}{c}\text { Sorbitol } \\
(\mathbf{g})\end{array}$ & $\begin{array}{c}\text { Acetone } \\
(\mathbf{m L})\end{array}$ \\
\hline LS1 & 6 & 2 & 0 & 0 & 0 & 0 & 300 \\
\hline LS2 & 6 & 0 & 2 & 0 & 0 & 0.4 & 300 \\
\hline LS3 & 6 & 0 & 0 & 2 & 0 & 0.8 & 300 \\
\hline LS4 & 6 & 0 & 0 & 0 & 2 & 1.2 & 300 \\
\hline LD5 & 6 & 0 & 0 & 0 & 0 & 1.2 & 300 \\
\hline
\end{tabular}

\section{Evaluation of Controlled Porosity Osmotic Pump Tablets}

Pre compression parameters of osmotic pump tablets [11]

Angle of repose $\theta$ : The angle of repose was determined by the funnel method. The accurately weighed powder blend was taken in a funnel. The height of the funnel was adjusted in such a way that the tip of the funnel just touched the apex of the heap of the powder blend. The blends were allowed to flow freely onto the surface (Table 3). The diameter of the powder cone was measured. Angle of repose is calculated using the following equation:

$\tan \theta=h / r$

$\theta=\tan ^{-1}(h / r)$

Where $\boldsymbol{\theta}$ is the angle of repose, $\mathrm{h}$ is the height of heap in $\mathrm{cm}$ and $r$ is the radius of the circular support (cone) in $\mathrm{cm}$.

Bulk density $\left(\mathbf{e}_{\mathbf{b}}\right)$ : Bulk density is determined by pouring the granules into a graduated cylinder of bulk density apparatus (Sisco, India). The bulk volume $\left(\mathrm{V}_{\mathrm{b}}\right)$ and mass $(\mathrm{m})$ of the granules is determined. The bulk density is calculated by using the following formula.

$\mathrm{e}_{\mathrm{b}}=\frac{\mathrm{m}}{V_{b}}$

Tapped density $\left(\mathbf{e}_{\mathbf{t}}\right)$ : The measuring cylinder containing known mass of granules blend is tapped 1000 times for a fixed time in bulk density apparatus (Sisco, India). The minimum volume occupied in the cylinder $\left(\mathrm{V}_{t}\right)$ and mass of the granules $(m)$ is measured. The tapped density is measured by using the following formula.

$e_{t}=\frac{m}{V_{t}}$

Compressibility index (Carr's index): The compressibility index determines the flow property characteristics of granules developed by Carr. The percentage compressibility of granules is a direct measure of the potential powder arch and stability (Table 3). The Carr's index can be calculated by the following formula.

$\%$ Carr's index $=\frac{\mathrm{e}_{\mathrm{t}}-\mathrm{e}_{\mathrm{b}}}{\mathrm{e}_{\mathrm{t}}} \times 100$

Where $e_{t}$ is the tapped density of granules and $e_{b}$ is bulk density of granules.

Hausner's ratio $\left(\mathbf{H}_{\mathbf{R}}\right)$ : Hausner's ratio is used for the determination of flow properties of granules (Table 3). The ratio can be calculated by taking the ratio of tapped density to the ratio of bulk density.

$H_{R}=\frac{e_{t}}{\mathrm{e}_{\mathrm{b}}}$

Table 3. Scale of flowability determined by different methods [12]. \begin{tabular}{|l|l|l|l|}
\hline Flow property & Angle of repose & Compressibility index & Hausner's ratio \\
\hline
\end{tabular}

\begin{tabular}{|l|c|c|c|}
\hline Excellent & $25-30$ & $\leq 10$ & $1.00-1.11$ \\
\hline Good & $31-35$ & $11-15$ & $1.12-1.18$ \\
\hline Fair & $36-40$ & $16-20$ & $1.19-1.25$ \\
\hline Passable & $41-45$ & $21-25$ & $1.26-1.34$ \\
\hline Poor & $46-55$ & $26-31$ & $1.35-1.45$ \\
\hline Very poor & $56-65$ & $32-37$ & $1.46-1.59$ \\
\hline Very very poor & $>66$ & $>38$ & $>1.6$ \\
\hline
\end{tabular}

Post compression parameters of controlled porosity osmotic pump tablets [13]

Thickness: The thickness of individual tablets is measured by using vernier caliper (Mitutoyo Corp., Japan) which gives the accurate measurement of thickness in $\mathrm{mm}$. The limit of the thickness deviation of each tablet is $\pm 5 \%$.

Measurement of coat thickness: After dissolution the film was isolated from the tablets and dried at $40^{\circ} \mathrm{C}$ for $1 \mathrm{hr}$. Thickness was measured by using electronic digital calipers (Mitutoyo Corp., Japan) and mean values were taken.

Hardness: The hardness of tablets can be determined by using Monsanto hardness tester (Sisco, India) and measured in terms of $\mathrm{kg} / \mathrm{cm}^{2}$.

Friability: Friability of tablets was performed in a Roche friabilator (Sisco, India). Twenty tablets of known weight $\left(\mathrm{W}_{0}\right)$ were de-dusted in plastic chamber of friabilator for a fixed time of $25 \mathrm{rpm}$ for 4 minutes and weighed again of weight (W). The percentage of friability was calculated using the following equation.

$\%$ Friability $=\mathrm{F}=\left(1-\frac{\mathrm{W}}{\mathrm{W}_{0}}\right) \times 100$

Where, $W_{0}$ and $W$ are the weight of the tablets before and after the test respectively. 


\section{Weight variation test [14]}

The weight variation test is done by weighing 20 tablets individually calculating the average weight and comparing the individual tablet weights to the average. The percentage weight deviation was calculated and then compared with USP specifications.

\section{Uniformity of drug content test}

Ten tablets from each batch of CPOP formulations were taken and triturated to form powder. The powder weight equivalent to one tablet was dissolved in a $100 \mathrm{ml}$ volumetric flask filled with $0.1 \mathrm{~N} \mathrm{HCl}$ using magnetic stirrer for $24 \mathrm{hr}$. Solution was filtered through Whatman filter paper No.1 diluted suitably and analyzed spectrophotometrically.

\section{Diameter of tablet}

The diameter of individual tablets is measured by using vernier caliper (Mitutoyo Corp., Japan) which gives the accurate measurement of diameter in $\mathrm{mm}$.

\section{In vitro dissolution studies}

The in vitro dissolution studies were carried out using USP apparatus type II (Lab India 8000) at $75 \mathrm{rpm}$. For the first $2 \mathrm{hr}$ the dissolution medium was $0.1 \mathrm{~N} \mathrm{HCl}(\mathrm{pH} \mathrm{1.2)}$ and phosphate buffer $\mathrm{pH} 6.8$ from $3-12 \mathrm{hr}(900 \mathrm{ml})$, maintained at $37 \pm 0.5^{\circ} \mathrm{C}$. At each time point $5 \mathrm{ml}$ of sample was withdrawn and it was replaced with $5 \mathrm{ml}$ of fresh medium. The drug release at different time interval was measured by UV-visible spectrophotometer (UV-1800, Shimadzu, Japan).

\section{In vitro drug release kinetic studies $[15,16]$}

In order to investigate the mode of release from tablets, the release data of optimized formulation was analyzed zero order kinetics, first order kinetics, Higuchi model, KorsmeyerPeppas and Hixson-Crowell equations.

\section{Effect of osmogen concentration [17]}

To check the effect of osmogen concentration on drug release formulations were prepared with different concentration of osmotic agents and all other parameters of tablet kept constant. The drug release was compared with the different osmogen concentration of formulated batches by using USP-II dissolution apparatus.

\section{Effect of pore former concentration [18]}

Different concentrations of pore former were used in semi permeable membrane formation. In order to compare the effect of pore former on in vitro release profile as well as number of formation of micropores were compared.

\section{Effect of membrane thickness [19]}

Tablets with varying coating thicknesses were prepared to demonstrate the effect of coating thickness on drug release. The drug release rate was measured using $0.1 \mathrm{~N} \mathrm{HCl}$ and phosphate buffer $\mathrm{pH} 6.8$ as a dissolution medium.

\section{Effect of osmotic pressure [20]}

To increase the osmotic pressure of the release media pre-equilibrated to $37^{\circ} \mathrm{C} \pm 1^{\circ} \mathrm{C}$ temperature and osmotically effective solute mannitol was added to produce $30 \mathrm{~atm}, 60$ atm and 90 atm respectively. The drug release rate was tested and compared for various dosage forms.

\section{Effect of pH [21]}

In order to study the effect of $\mathrm{pH}$ of release medium in the drug release of optimized formulation, the in vitro release study was carried in dissolution media having different $\mathrm{pH}$ media. Dissolution can be carried in $900 \mathrm{ml}$ of $0.1 \mathrm{~N} \mathrm{HCl}, \mathrm{pH}$ 6.8 phosphate buffer and $\mathrm{pH} 7.4$ phosphate buffer in USP type II dissolution apparatus in $75 \mathrm{rpm}$. The temperature was maintained at $37 \pm 0.5^{\circ} \mathrm{C}$. The release was studied at predetermined time intervals.

\section{Effect of agitation intensity [22]}

To study the effect of agitation intensity on drug release, optimized formulation was subjected to dissolution at various rotation speeds. Dissolution was carried out in USP-II (Paddle) at 50, 100 and $150 \mathrm{rpm}$. The samples were withdrawn at predetermined intervals and analyzed by UV spectrometer.

\section{Scanning Electron Microscopy (SEM) [23]}

In order to observe the mechanism of drug release from the developed formulations surface coated tablets before and after dissolution studies was examined using scanning electron microscope. Scans were taken at an excitation voltage (KV) in SEM fitted with ion sputtering device.

\section{Accelerated stability studies [24]}

The packed tablets in air tight container were placed in stability chambers (Thermo lab Scientific equipment Pvt. Ltd. Mumbai, India) maintained at $40 \pm 2^{\circ} \mathrm{C} / 75 \pm 5 \% \mathrm{RH}$ conditions for accelerated testing) for 3 months. Tablets were periodically removed and evaluated for physical characteristics, drug content, in-vitro drug release etc.

\section{Results and Discussion}

\section{FTIR studies}

The study of the FTIR spectra of lamivudine demonstrated that the characteristic absorption peaks for the $\mathrm{C}-\mathrm{H}$ stretching at $2843.83 \mathrm{~cm}^{-1}, \mathrm{~N}-\mathrm{H}$ bending at $1640.32 \mathrm{~cm}^{-1}, \mathrm{C}-\mathrm{N}$ stretching at $1010.71 \mathrm{~cm}^{-1}, \mathrm{O}-\mathrm{H}$ in plane bending at $1054.55 \mathrm{~cm}^{-1}$ and amine group stretching at $3326.6 \mathrm{~cm}^{-1}$. This further confirms the purity of lamivudine.

The major peaks of HPMCE5LV were found at 3880.71, $3810.87,3713.83,3669.20,3566,3117.03,3066.96,2982.59$, 2887.86, 2847.2, 2803.12, 2710.75, 2618.99, 2444.13, 2335.14, 2068.70, 1661.47, 1536.52, 1500.67, 1424.62, 1071.87, 781.05 and $584.97 \mathrm{~cm}^{-1}$. The major peaks of sodium chloride were found at 3398.38, 2133.90, 2062.19, 1787.75, 1187.17, 906.53 and $634.66 \mathrm{~cm}^{-1}$. In the optimized formulation containing sodium chloride of osmotic pump (LS4) peak at 3669.81, 3054.80 , and $795.27 \mathrm{~cm}^{-1}$ were due to presence of the polymer HPMCE5LV. In the formulation the peaks present due to sodium chloride were 1779.97 and $613.23 \mathrm{~cm}^{-1}$. Peaks at 2124.12 , and $1649.61 \mathrm{~cm}^{-1}$ were due to presence of the drug lamivudine in the optimized formulation. So from the study it can be concluded that the major peaks of drug 2124.12, and 
$1649.61 \mathrm{~cm}^{-1}$ remain intact and no interaction was found between the drug, polymer and osmogen. Hence drugexcipient mixture reveals that here is no incompatibility was observed between lamivudine (Figures 1 and 2).

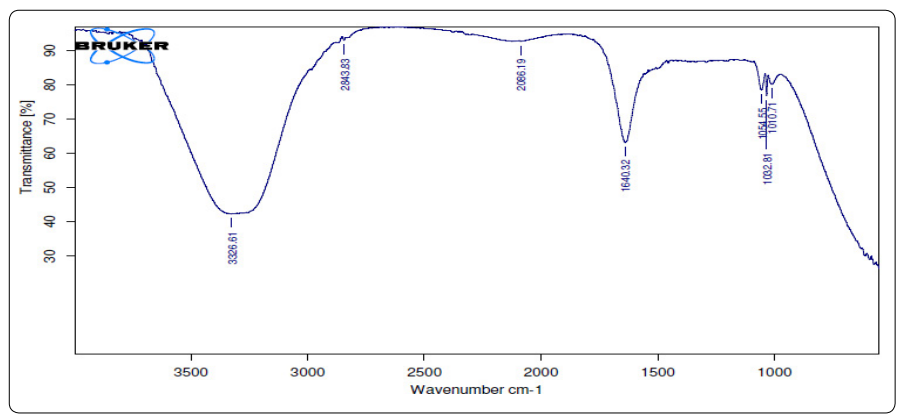

Figure 1. FTIR spectroscopy study of pure Lamivudine

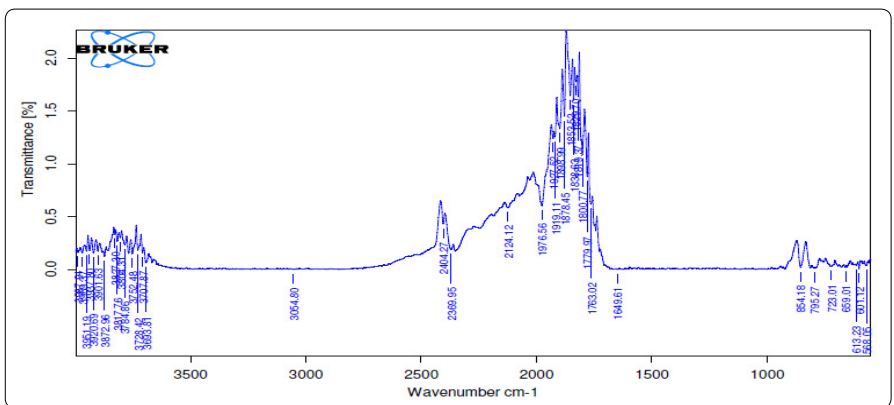

Figure 2: FTIR spectroscopy study of LS4

\section{DSC Thermograms}

From the figure 3 it was found that the endothermic peak of lamivudine was at $162.2^{\circ} \mathrm{C}$. The endothermic peak of LS4 formulation (Figure 4) was observed at $161.3^{\circ} \mathrm{C}$. No significant change in the endotherm was observed between drug and formulation. From the DSC thermograms it was clear that no specific interaction between the drug and excipients used in present formulation.

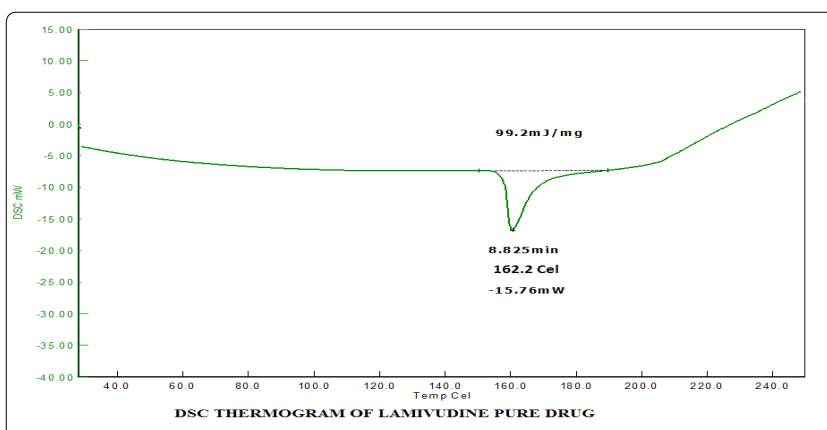

Figure 3. DSC thermo gram of Lamivudine

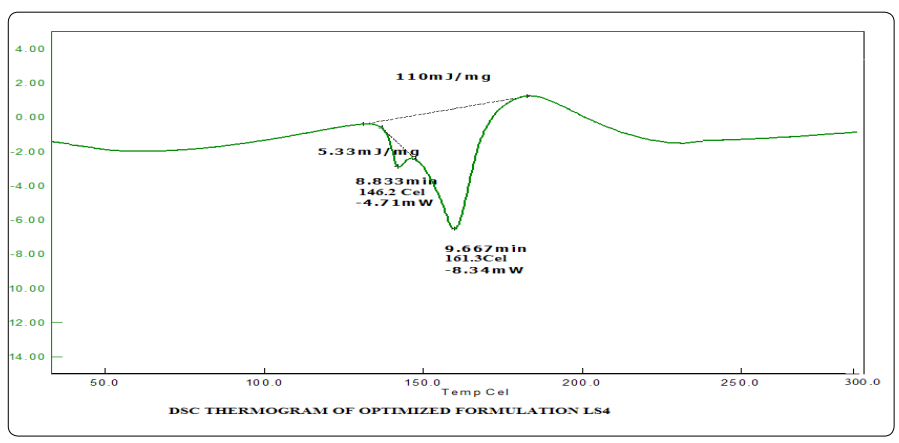

Figure 4. DSC thermo gram of LS4

\section{Pre compression parameters}

All the compressible excipients for various batches were evaluated for angle of repose, bulk density, tapped density, Carr's index and Hausner's Ratio. The angle of repose of precompression blends of various batches was in the range of $24.96 \pm 0.06$ to $28.17 \pm 0.05$. The bulk density of pre-compression blends was found to be in the range of $0.502 \pm 0.12$ to $0.528 \pm$ $0.12 \mathrm{gm} / \mathrm{ml}$, tapped density in the range of $0.537 \pm 0.04$ to $0.562 \pm 0.11 \mathrm{gm} / \mathrm{ml}$, the Carr's index values were in the range of $5.77 \pm 0.02$ to $7.72 \pm 0.09$, and Hausner's ratio values were ranges of $1.06 \pm 0.02$ to $1.08 \pm 0.11$. It is given in table 4 .

Table 4. Pre compression parameters of LM formulations

\begin{tabular}{|l|c|c|c|c|c|}
\hline $\begin{array}{l}\text { Formulation } \\
\text { code }\end{array}$ & $\begin{array}{c}\text { Angle of } \\
\text { repose } \\
\left(\begin{array}{c}\text { degree })^{\mathrm{a}} \pm \\
\text { S.D }\end{array}\right.\end{array}$ & $\begin{array}{c}\text { Bulk density } \\
(\mathrm{g} / \mathrm{ml})^{\mathrm{a}} \pm \\
\text { S.D }\end{array}$ & $\begin{array}{c}\text { Tapped } \\
\text { density } \\
(\mathrm{g} / \mathrm{ml})^{\mathrm{a}} \pm \text { S.D }\end{array}$ & $\begin{array}{c}\text { Carr's Index } \\
(\%)^{\mathrm{a}} \pm \text { S.D }\end{array}$ & $\begin{array}{c}\text { Hausner's } \\
\text { Ratio } \pm \\
\text { S.D }\end{array}$ \\
\hline LS1 & $28.17 \pm 0.05$ & $0.502 \pm 0.12$ & $0.544 \pm 0.14$ & $7.72 \pm 0.09$ & $1.08 \pm 0.11$ \\
\hline LS2 & $27.16 \pm 0.14$ & $0.509 \pm 0.12$ & $0.545 \pm 0.11$ & $6.60 \pm 0.09$ & $1.07 \pm 0.16$ \\
\hline LS3 & $28.12 \pm 0.13$ & $0.513 \pm 0.13$ & $0.546 \pm 0.12$ & $6.04 \pm 0.01$ & $1.06 \pm 0.06$ \\
\hline LS4 & $24.96 \pm 0.06$ & $0.506 \pm 0.08$ & $0.537 \pm 0.04$ & $5.77 \pm 0.02$ & $1.06 \pm 0.02$ \\
\hline LD5 & $26.19 \pm 0.11$ & $0.528 \pm 0.12$ & $0.562 \pm 0.11$ & $6.05 \pm 0.14$ & $1.06 \pm 0.09$ \\
\hline
\end{tabular}

N.B-All values are expressed as mean \pm S.D, ${ }^{a} n=3$.

\section{Post compression parameters}

All the post compression parameters for various batches evaluated accordingly such as thickness, coat thickness, hardness, friability, weight variation, drug content and diameter of tablet etc. The thickness of formulated tablets was found to be in the range of $3.502 \pm 0.02$ to $3.569 \pm 0.03$ $\mathrm{mm}$, coat thickness in the range of $100.3 \pm 2.4$ to $250.6 \pm 2.9$ $\mu \mathrm{m}$, the hardness values were in the range of $7.6 \pm 0.04$ to 8.3 $\pm 0.12 \mathrm{~kg} / \mathrm{cm}^{2}$, the friability values were in range of $0.12 \pm$ 0.12 to $0.20 \pm 0.14$, average weight of tablet was in the range of $649.9 \pm 1.4$ to $651.8 \pm 1.2 \mathrm{mg}$, drug content of tablet was in the range of $98.17 \pm 1.05$ to $100 \pm 1.14$ and diameter of tablets values were ranges of $11.98 \pm 0.04$ to $12.29 \pm 0.03$ $\mathrm{mm}$. It is mentioned in table 5 .

Table 5. Post compression parameters of controlled porosity osmotic pump tablets

\begin{tabular}{|c|c|c|c|c|c|c|c|}
\hline 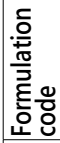 & 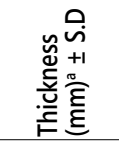 & 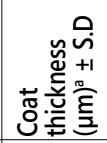 & 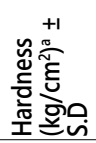 & 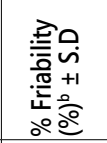 & 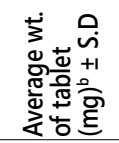 & 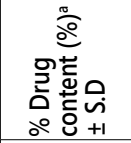 & 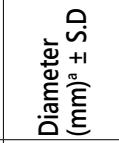 \\
\hline LS1 & $3.563 \pm 0.04$ & $250.6 \pm 2.9$ & $7.6 \pm 0.04$ & $0.20 \pm 0.14$ & $649.9 \pm 1.4$ & $99.74 \pm 1.11$ & $11.98 \pm 0.04$ \\
\hline LS2 & $3.569 \pm 0.03$ & $200.4 \pm 3.1$ & $7.8 \pm 0.05$ & $0.17 \pm 0.12$ & $650.9 \pm 1.3$ & $98.17 \pm 1.05$ & $12.21 \pm 0.05$ \\
\hline LS3 & $3.568 \pm 0.04$ & $150.3 \pm 2.5$ & $8.1 \pm 0.16$ & $0.13 \pm 0.11$ & $651.8 \pm 1.2$ & $98.438 \pm 1.06$ & $12.16 \pm 0.03$ \\
\hline LS4 & $3.502 \pm 0.02$ & $100.3 \pm 2.4$ & $8.3 \pm 0.12$ & $0.12 \pm 0.14$ & $650.02 \pm 1.3$ & $100 \pm 1.14$ & $12.03 \pm 0.01$ \\
\hline LD5 & $3.509 \pm 0.01$ & $150.5 \pm 2.6$ & $8.0 \pm 0.02$ & $0.12 \pm 0.12$ & $650.07 \pm 1.03$ & $98.958 \pm 1.06$ & $12.29 \pm 0.03$ \\
\hline
\end{tabular}

\section{In vitro drug dissolution study}

The in vitro drug release characteristics were studied in $900 \mathrm{ml}$ of $0.1 \mathrm{~N} \mathrm{HCl}(\mathrm{pH} 1.2)$ for a period of first 2 hrs and 3 to 12 hrs in phosphate buffer $\mathrm{pH} 6.8$ using USP type II dissolution apparatus (Paddle type). The cumulative percentage drug release for LS1, LS2, LS3, LS4 and LD5 were 91.92, 92.48, 93.71, 98.26 and $85.89 \%$ respectively of lamivudine at the end of 12 hrs. It is shown in figure 5 . The same figure gives about effect of osmogen concentration, pore former and membrane thickness. 


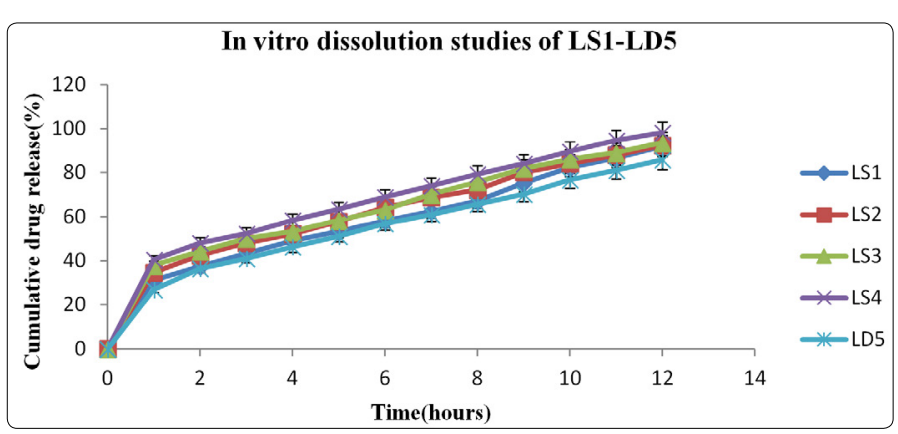

Figure 5. In vitro release profiles showing lamivudine release from various fabricated formulations LS1-LD5

\section{Kinetic model}

The drug release kinetics from the porous osmotic pump tablet, the in vitro release data were analyzed by zero order, first order, Higuchi and Korsmeyer and Peppas equations and Hixson-Crowell equation. The optimized formulation is showing highest regression values $\left(R^{2}\right)$ in Higuchi model (0.984) than zero order and first order. Hence the drug release follows Higuchi kinetics. The $n$ value for optimized formulation is $0.369(n<0.45)$, hence it follows Fickian diffusion mechanism. It is indicated in table 6.

Table 6. Fitting of IVDR data in various mathematical models

\begin{tabular}{|c|c|c|c|c|c|c|c|c|c|c|c|}
\hline \multirow{2}{*}{\begin{tabular}{|c|}
$\frac{n}{0}$ \\
$\frac{\mathbb{v}}{\delta}$ \\
$\sum$ \\
Batches
\end{tabular}} & \multicolumn{2}{|c|}{ 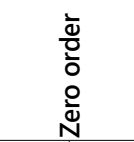 } & \multicolumn{2}{|c|}{ 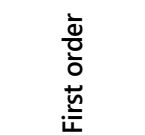 } & \multicolumn{2}{|c|}{$\begin{array}{l}\text { 空 } \\
\text { 产 }\end{array}$} & \multicolumn{3}{|c|}{ 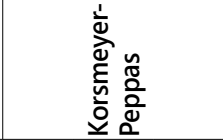 } & \multicolumn{2}{|c|}{ 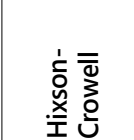 } \\
\hline & $R^{2}$ & $\mathrm{~K}_{0}$ & $\mathrm{R}_{1}^{2}$ & $\mathrm{~K}_{1}$ & $\mathrm{R}_{\mathrm{H}}{ }^{2}$ & $\mathrm{~K}_{\mathrm{H}}$ & $\mathrm{R}_{\mathrm{K}}{ }^{2}$ & $\mathrm{Kp}$ & $\mathrm{n}$ & $\mathrm{R}^{2}$ & Ks \\
\hline LS1 & 0.934 & 6.318 & 0.924 & 0.1750 & 0.982 & 25.02 & 0.962 & 27.861 & 0.443 & 0.961 & 0.186 \\
\hline LS2 & 0.905 & 6.239 & 0.953 & 0.1819 & 0.989 & 25.20 & 0.975 & 31.915 & 0.405 & 0.973 & 0.191 \\
\hline LS3 & 0.895 & 6.255 & 0.947 & 0.1934 & 0.983 & 25.32 & 0.958 & 34.119 & 0.381 & 0.969 & 0.198 \\
\hline LS4 & 0.884 & 6.459 & 0.867 & 0.2625 & 0.984 & 26.32 & 0.968 & 36.982 & 0.369 & 0.952 & 0.235 \\
\hline LD5 & 0.932 & 5.960 & 0.968 & 0.1404 & 0.992 & 23.75 & 0.985 & 25.585 & 0.462 & 0.977 & 0.160 \\
\hline
\end{tabular}

\section{Effect of osmogen concentration}

The core formulations were prepared with various concentrations of osmogens. The drug release profile is shown in figure 5 . It is observed that osmogent enhances the drug release of drug and thus had a direct effect on drug release. The concentrations of osmogen were $0,25,50,75$ and $100 \mathrm{mg} /$ tablet for LD5, LS1, LS2, LS3 and LS4 respectively. The cumulative percentage drug release for LS1, LS2, LS3, LS4 and LD5 were 91.92, 92.48, 93.71, 98.26 and 85.89\% respectively of lamivudine at the end of $12 \mathrm{hrs}$.

\section{Effect of pore former}

Release profile from prepared formulations is shown in figure 5 . It is clearly evident that the level of sorbitol had a direct effect on drug release. As the level of pore former increases the membrane becomes more porous after coming contact with aqueous environment resulting in faster drug release.

\section{Effect of membrane thickness}

The osmotic pump coated tablets having varying the coating thickness are evaluated for drug release study. Release profile of lamvudine from these formulations is shown in figure 5 . It is clearly evident that drug release decreases with increase in coating thickness of the semi permeable membrane.

\section{Effect of osmotic pressure}

The results of release studies of optimized formulation in media of different osmotic pressure indicated that the drug release is highly dependent on the osmotic pressure of the release media. The release was inversely related to the osmotic pressure of release media. This finding confirms that the mechanism of drug release is by osmotic pressure. The drug release for LS4 was found to be $90.54 \%$ for 30 atm, $81.46 \%$ for 60 atm and $72.67 \%$ for 90 atm respectively. It is shown in figure 6 .

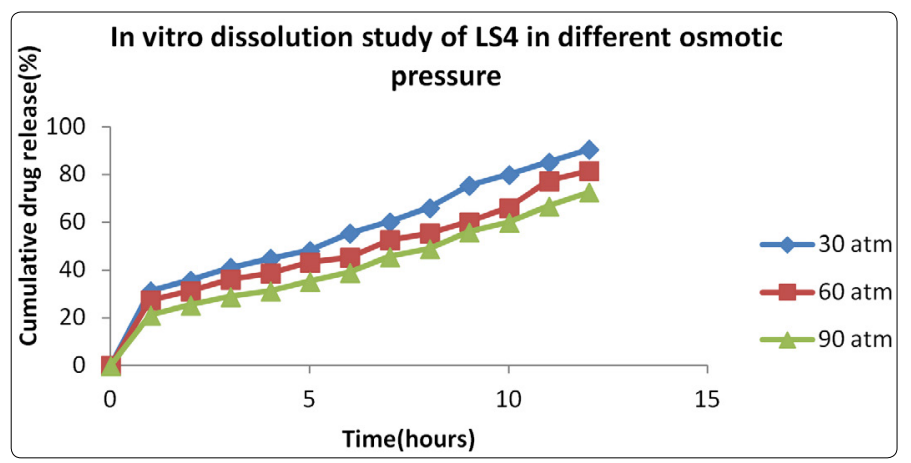

Figure 6. In vitro release profiles showing lamivudine release from optimized LS4 in different osmotic pressures

\section{Effect of pH}

The optimized formulation LS4 was subjected to in vitro drug release studies in buffers with different $\mathrm{pH}$ like $\mathrm{pH} 1.2, \mathrm{pH} 6.8$ and $\mathrm{pH7.4}$. It is observed that there is no significant difference in the release profile, demonstrating that the developed formulation shows $\mathrm{pH}$ independent release. It is shown in figure 7.

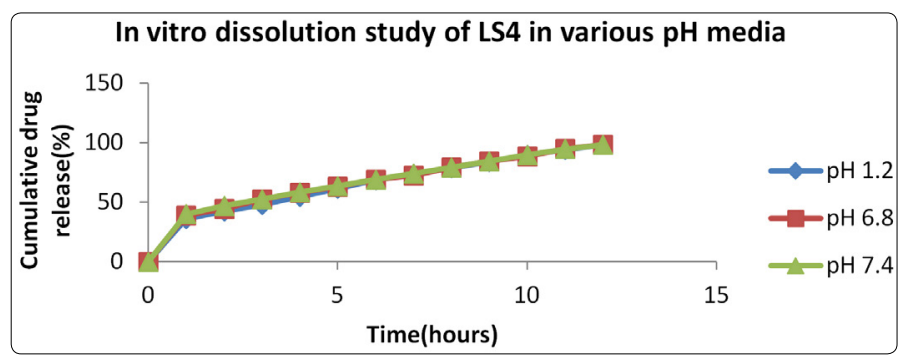

Figure 7. In vitro dissolution study of optimized formulation LS4 in various $\mathrm{pH}$ media

\section{Effect of agitation intensity}

The optimized formulation of LS4 batch was carried out in USP dissolution apparatus type-II at varying rotational speed $(50,100$ and $150 \mathrm{rpm})$. It shows that the release of lamivudine from CPOP is independent of agitational intensity. Hence it can be expected that the release from the developed formulation will be independent of the hydrodynamic conditions of the absorption site. It is shown in figure 8 .

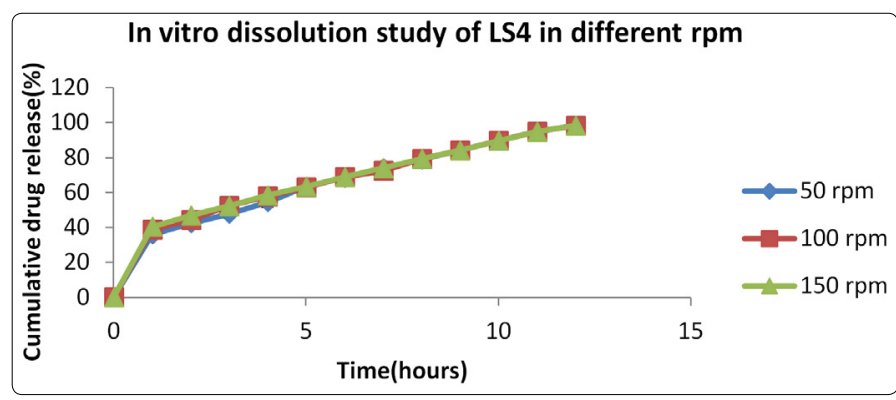

Figure 8. In vitro dissolution study of optimized formulation LS4 in various agitation speed 


\section{SEM analysis}

Before dissolution fewer pores were found in the coating membrane. But after dissolution comparatively more numbers of pores were found in the membrane might be due to leaching or removal of entrapped drug from the formulation. The porosity nature of the membrane was due to the presence of pore forming agent sorbitol in the formulation (Figures 9a and 9b).
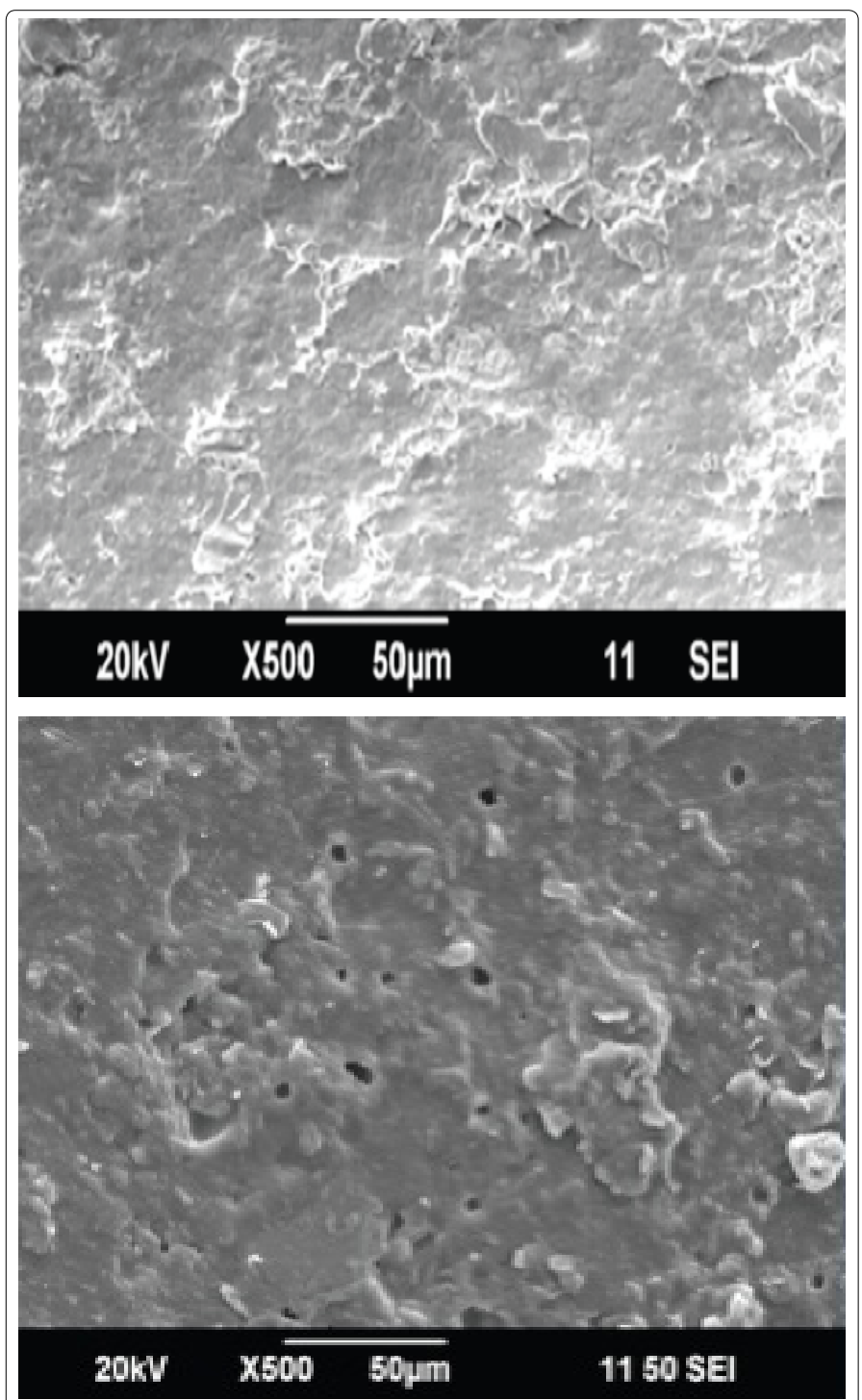

Figure 9. (a) SEM image of LS4 before dissolution (b) SEM image of LS4 after dissolution

\section{Stability Studies}

From short term stability studies of optimized formulation LS4, it was confirmed that there was no significance changes in physical appearance, thickness, hardness, friability, weight variation drug content and \% drug release.

\section{Conclusion}

CPOP tablets can be designed for controlled release of lamivudine using wet granulation technique. It was evident from the results that rate of drug release can be controlled through osmotic pressure of the core, the level of pore former. From the developed formulations the release of lamivudine was best in LS4 formulation. The result of SEM studies confined the formation of pores in the membrane after coming into contact with the aqueous environment.

\section{Acknowledgements}

The authors would like to acknowledge the contributions of Pharmaceutics department, Faculty of Pharmacy, University College of Technology, Osmania University, Hyderabad, India for providing necessary facilities to carry out the research work. This study was part of a Ph.D thesis under Osmania University, Hyderabad.

\section{References}

1. Barre Sinoussi F, Chermann JC, Rey F, et al. Isolation of a T lymphotropic retrovirus from a patient at risk for acquired immune deficiency syndrome(AIDS). Science. 1983; 220: 868-871.

2. UNAIDS. Review of data from People Living with HIV Stigma Index surveys conducted in more than 65 countries. 2016.

3. Cohen MS, Gay CL, Busch MP, Hecht FM. The detection of acute HIV infection. J Infect Dis. 2010; 15(202): 270-277. doi: 10.1086/655651

4. Chein YW. Novel Drug Delivery Systems. Marcel Dekker, Inc., New York, USA. 1992: 139-196.

5. Verma RK, Krishna DM, Garg S. Formulation aspects in the development of osmotically controlled oral drug delivery systems. J Control Release. 2000; 79: 7-27.

6. Richman DD. HIV chemotherapy. Nature. 2001; 410: 995-1001. doi: 10.1038/35073673

7. Jadav MM, Teraiya SR, Patel KN, Patel BA, Patel PA. Formulation and Evaluation of Oral Controlled Porosity Osmotic Pump Tablet of Zaltoprofen. International Journal for Pharmaceutical Research Scholars. 2012; 1(2): 254-267.

8. Edavalath S, Shivanand K, Prakasam K, Rao BP, Divakar G. Formulation development and optimization of controlled porosity osmotic pump tablets of diclofenac sodium. Int J Pharm Pharm Sci. 2011; 3(1): 80-87.

9. Banerjee A,Verma PRP, Gore S. Controlled porosity solubility modulated osmotic pump tablets of Gliclazide. AAPS Pharm Sci Tech. 2015; 16(3): 554-568.

10. Sahoo CK, Sahoo TK, Moharana AK, Panda KC. Formulation and optimization of porous osmotic pump based controlled release system of Residronate sodium for the treatment of postmenopausal osteoporosis. International Journal of Pharmaceutical Sciences Review and Research. 2012; 12(1): 118-122.

11. Sahoo CK, Sahoo NK, Rao SRM, Sudhakar M, Satyanarayana K. A review on controlled porosity osmotic pump tablets and its evaluation. Bulletin of Faculty of Pharmacy, Cairo University. 2015; 53 (2):1 95-205

12. Sunil SA, Srikanth MV, Rao NS, Balaji S, Murthy KVR. Design and evaluation of lornoxicam bilayered tablets for biphasic release. Brazilian Journal of Pharmaceutical Sciences. 2012; 48(4): 609-619.

13. Sahoo CK, Rao SRM, Sudhakar M. Evaluation of controlled porosity osmotic pump tablets: a review. Research J. Pharm. and Tech. 2015; 8(12): 119-125. doi: 10.5958/0974-360X.2015.00312.1

14. Pawar $A H$, Dhavale R. Development and evaluation of gastroretentive floating tablets of an antidepressant drug by thermoplastic granulation technique. Beni-suef University Journal of Basic and Applied Sciences. 2014; 3: 122-132. doi: 10.1016/j.bjbas.2014.05.005

15. Sahoo CK, Rao SRM, Sudhakar M, Kokkula S. The kinetic modeling of drug dissolution for drug delivery systems: an overview. Der Pharmacia Lettre. 2015; 7(9): 186-194.

16. Costa P, Lobo JMS. Modelling and comparision of dissolution profiles. European Journal of Pharmaceutical Sciences. 2001; 13: 123-133. doi: 10.1016/S0928-0987(01)00095-1 
17. Kumaravelrajan R, Narayanan N, Suba V. Development and evaluation of controlled porosity osmotic pump for Nifedipine and Metoprolol combination. Lipids Health Dis. 2011; 10: 51. doi: 10.1186/1476-511X-10-51

18. Dasankoppa FS, Ningangowdar M, Sholapur H. Formulation and evaluation of controlled porosity osmotic pump for oral delivery of ketorolac. J Basic Clin Pharm. 2013; 4(1): 2-9. doi: 10.4103/0976-0105.109398

19. Kanagale P, Lohray BB, Misra A, Davadra P, Kini R. Formulation and Optimization of Porous Osmotic Pump based Controlled Release System of Oxybutynin. AAPS Pharm Sci Tech. 2007; 8(3): 1-7. doi: 10.1208/ pt0803053

20. Shah N, Patel K. Design and development of controlled porosity osmotic tablets of captopril. Journal of Pharmaceutical Science and Bioscientific Research. 2013; 3(4): 145-150.
21. Rani $M$, Mishra B. Comparative in vitro and in vivo evaluation of matrix osmotic matrix and osmotic pump tablets for controlled delivery of diclofenac sodium. AAPS Pharm Sci Tech. 2004; 5(4): 1-7. doi: 10.1208/pt050471

22. Maheswari U, Elango K, Chellakumari D, Saravanan K, Samy AJ. Formulation and evaluation of controlled porosity osmotic tablets of lornoxicam. International Journal of Pharmaceutical Sciences and Research. 2012; 3(6): 1625-1631. doi: 10.13040/IJPSR.0975-8232

23. Khan ZA, Tripathi R, Mishra B. Design and evaluation of enteric coated microporous osmotic pump tablet(ECMOPT) of quetiapine fumarate for the treatment of psychosis. Acta Poloniae-Drug Research 2012; 69(6): $1125-1136$.

24. Sharma F, Jain H, Kanzariya V, Upadhyay U. Formulation and evaluation of controlled release osmotic tablet of metoprolol succinate. Asian J Pharm Clin Res. 2014; 7(3): 38-43. 